\title{
Article
}

\section{The effects of functional instability of the ankle joint on balance}

Kim, Yongwook, Kim, Eunji, Song, Yegeurin, Han, Dahye and Richards, Jim

Available at http://clok.uclan.ac.uk/12819/

Kim, Yongwook, Kim, Eunji, Song, Yegeurin, Han, Dahye and Richards, Jim ORCID: 0000-0002-4004-3115 (2016) The effects of functional instability of the ankle joint on balance. Physiotherapy Practice and Research, 37 (1). pp. 39. ISSN 2213-0683

It is advisable to refer to the publisher's version if you intend to cite from the work. http://dx.doi.org/10.3233/PPR-150066

For more information about UCLan's research in this area go to http://www.uclan.ac.uk/researchgroups/ and search for <name of research Group>.

For information about Research generally at UCLan please go to http://www.uclan.ac.uk/research/

All outputs in CLoK are protected by Intellectual Property Rights law, including Copyright law. Copyright, IPR and Moral Rights for the works on this site are retained by the individual authors and/or other copyright owners. Terms and conditions for use of this material are defined in the policies page.

\section{CLoK}

Central Lancashire online Knowledge www.clok.uclan.ac.uk

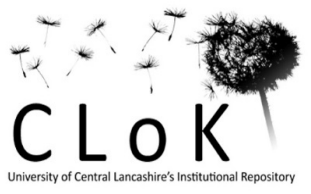


Title: The effects of Functional Instability of the Ankle Joint on Balance Yongwook Kim ${ }^{1}$, Eunji Kim ${ }^{1}$, Yegeurin Song ${ }^{1}$, Dahye Han $^{1}$, Jim Richards ${ }^{2}$

${ }^{1}$ Department of Physical Therapy, College of Medical Sciences, Jeonju University.

${ }^{2}$ Allied Health Research unit, University of Central Lancashire.

Corresponding author and reprint requests to Prof Jim Richards, PhD,

Address correspondence to Prof Jim Richards, Allied Health Research unit, University of

Central Lancashire, Brook Building, Preston, Lancashire, UK, PR1 2HE

TEL:+44 (0) 1772-89-4575, E-mail: jrichards@uclan.ac.uk

\section{Abstract}


Background: Individuals who suffer from ankle instability may experience restricted movement and a weakening of the muscles that support the ankle.

Purpose: The aim of this study was to investigate the effects of functional instability of the ankle joint on static and dynamic balance performances.

\section{Basic Methods}

Twenty-five participants ( 8 male, 17 female) were recruited for this study. The subjects were divided into two groups: an ankle instability and a normal ankle stability group. The static and dynamic limits of stability performance were assessed in single leg standing using the BioRescue device. In addition, the Functional Reach Test (FRT) and the Modified Functional Reach Test (MFRT) were also recorded.

\section{Main Results}

Significant differences between the two groups were found in the moving distance and the mean velocity of the center of pressure during the single leg standing test, the pendular limits of stability test, and the MFRT. However, the FRT showed no significant difference between the two groups. The results showed that the static and dynamic balance performances were reduced in the ankle instability group compared with the control group.

\section{Principal Conclusion}

Both the MFRT and BioRescue were sensitive and appropriate to pick clinically important differences between the two groups. The use of the MFRT is a quick and inexpensive clinical 
measure of postural instability relevant to individuals with ankle instability. Further studies should use the MFRT to determine the effectiveness of clinical interventions for ankle instability that target improvements in balance.

Key Words: Ankle instability, Balance, Modified functional reach test

\section{Introduction}

Functional instability of the talocrural joint is defined as being off balance due to an instability that causes repeated ankle sprains[1]. Those who suffer from this condition may experience restricted movement and a weakening of the muscles that support the ankle. Ankle sprains occur during physical activity, particularly during landing after a jump. They have a greater than $70 \%$ risk of reoccurring and can develop into chronic instability. Lateral ankle sprains, syndesmosis, and deltoid ligament sprains account for $85 \%, 10 \%$, and $5 \%$ of all ankle joint sprains, respectively. In addition, greater than $40 \%$ of lateral sprains can develop into chronic instability of the ankle joint[2]. Most ankle joint sprains cause inversion of the foot at the ankle plantar flexion, the anterior talofibular ligament represents the most commonly injured structure in an ankle sprain; it is involved in over $90 \%$ of all sprains[3]. In addition, ankle sprains have been shown to cause weakness of the tibialis anterior muscle as well as a decrease in proprioception and sensory deficit[4,5]. In particular, individuals feel balance 
instability during activities that require the ankle joints to support weight, including standing and walking. The cause of the functional instability in the ankle joints is not clearly understood but can be divided into epidemiological factors and functional factors[6]. Epidemiological factors can account for sports injuries, however ankle instability is the main functional factor. This can lead to subsequent partial deafferentiation of the proprioceptive reflex through damage to the lateral ligament and/or the mechanoreceptors of the muscles and tendons[6,7]. Thus, functional instability of the ankle joint is related to sensorimotor function, ankle evertor strength, ankle ligament tension, and deficient balance; which are the main causes of reoccurring ankle sprains[7-9].

Balance is the ability to maintain the centre of gravity (COG) on the base of support (BOS) in a given environment. Balance ability can be divided into static and dynamic balance. Maintaining posture and movement can be determined by the coordination of these two balance abilities[10]. Improving the ability to balance is critically important clinically to prevent reoccurring ankle joint sprains[11]. To maintain balance while performing functional activities, many complex factors are involved, including lower-extremity muscle strength, peripheral sensation, visual acuity, and proprioceptive reaction times[12].

The movement of the ankle joints plays an essential role in postural control[13], however, the most recent studies have investigated the intervention effects of functional instability of the ankle joints on postural control such as taping, exercises, or ankle 
orthoses[14-16]. This study aimed to evaluated static and dynamic balance performance in people with and without functional instability of the ankle joints to determine whether such balance tests are able to identify clinically important differences between these groups.

\section{Methods}

A sample size calculation was performed based on an estimated effect size derived from Daubney and Culham[17] who examined balance during FRT and a sample size of 10 in each group was determined to be sufficient to identify significant difference. A convenience sample of healthy participants without any limitations in their daily activities were recruited from a university population. We conducted a general self-reported foot and ankle function questionnaire of 178 people for the selection of research subjects. From the survey 25 adult volunteers who had consented to participate in the study and met the selection criteria were selected. All participants were fully informed about test methods, and the purpose study prior to testing. The study was approved by the Institutional Review Board of Jeonju University (jjIRB-2015-0109). The 25 subjects were divided into two groups: 10 were enrolled into the ankle functional instability (AFI) group and 15 into the ankle functional stability (AFS) group based on the dominant ankle joint. For inclusion criteria for the AFI group; individuals must have experienced at least three ankle sprains with the initial sprain occurring at least 12 months prior to participation, felt balance instability due to their ankles during daily living 
and had scored 26 or higher on the Ankle Joint Functional Assessment Tool (AJFAT)[18].

The AJFAT is a widely used tool for measuring the functional instability of the ankle joint. It consists of 12 categories, each measured on a scale of 0 to 4 points, giving a maximum of 48 points[19]. A high AJFAT score indicates a greater instability of the ankle joints. The selection criteria for the AFS group were: those who had no experience of ankle sprains before and who scored 20 points or lower in the AJFAT. The exclusion criteria were: previous lower limb surgery in either lower limb; previous fractures in either lower limb which required realignment; acute musculoskeletal injury in either lower limb in the previous 3 months[18].

A single leg standing test was conducted to evaluate the individual's static balance ability using BioRescue to determine the limits of stability and to evaluate the dynamic balance ability. BioRescue consists of a computer connected to 1,600 pressure sensors, each $10 \times 10 \mathrm{~mm}$, over and area of $610 \times 580 \mathrm{~mm}$ and displayed on a monitor of $93 \times 52 \mathrm{~cm}$. Data were collected at a sampling rate of $100 \mathrm{~Hz}$.

The experiment room was quiet and free from distractions during the assessments. The study subjects wore comfortable clothes and had bare feet during the test. Prior to the test, the required posture of each condition was explained and demonstrated to each subject. For all assessments an assistant was positioned close to subject to prevent falling during the test. The subjects placed their heels on the same line on the pressure plate according to the 
measurement tool manual and stood with a $30^{\circ}$ angle between their feet during the test (Figure 1).

The single leg standing test was repeated three times. The subjects were asked to stand on the BioRescue pressure plate and bend the knee on the contralateral side up to the popliteal region with their arm crossed (Figure 2), this posture was then maintained for 15 s during data collection. The surface area of the ellipse, the movement length and the mean velocity of the pressure center were used to determine the amount of postural sway.

The aim of the limits of the stability test was to measure the stability limit of the subject through weight movements in eight directions while standing on one leg. Subjects stood on one leg in the same posture while looking at the monitor. During this test hands were placed on the iliac crests and the arm movements were allowed to maintain balance. Once the test was initiated, the direction of weight movement required for the test was displayed on the monitor screen and the subjects moved their weight as far as they were able in the direction of the arrow. The eight weight movement directions were front, back, left, right, front left, back left, front right, and back right. The surface area of the ellipse was recorded throughout the test sequence.

For the functional reach test (FRT) the subjects were asked to reach as far forward as possible keeping their arms parallel and level with the ruler and without bending their knee and hip joint (Figure 3). The mean of the three trials was used for data analysis in accordance 
with a previous study which demonstrated test-retest reliability $($ ICC $=0.92)$ and inter-tester reliability $(\mathrm{ICC}=0.98)[20]$.

In the modified functional reach test (MFRT), the subjects were asked to abduct their shoulder to the level of the ruler and then instructed to reach as far to the side as possible without losing their balance, taking a step, or touching the wall (Figure 3). Three measurements were obtained and averaged in this analysis in accordance with previous work on the inter-rater reliability of the MFRT which reported ICC $=0.90-0.97[21]$.

An independent t-test and Mann-Whitney U-test were used before the experiment to assess differences in the general and medical characteristics of the two groups. The independent t-test was used to examine differences in the static and dynamic balance between the two groups. IBM SPSS (version 21.0) was used for statistical data processing with a statistical significance level of 0.05 .

\section{Results}

The mean age, height, weight, foot size, and AJFAT score in the AFI group (3 males and 7 females) were 21 years, 165.9 cm, $58.6 \mathrm{~kg}, 242.5 \mathrm{~mm}$, and 29.6 points, respectively, while those in the AFS group (5 males and 10 females) were 21.2 years, $166.3 \mathrm{~cm}, 58.3 \mathrm{~kg}$, $245.7 \mathrm{~mm}$, and 3.8 points, respectively (Table 1). The time since last ankle sprain was $3.4 \pm$ 2.2 months and the recallable number of ankle sprains was $4.2 \pm 1.3$ in the AFI group. During 
the static balance ability assessment, the surface area of the ellipse from the single leg standing test showed no significant difference between the groups $(\mathrm{p}=0.074,95 \% \mathrm{CI}=$ 308.70 16.72). However, the moving distance of the pressure centre and the mean velocity of the pressure centre showed a significant difference $(\mathrm{p}=0.001,95 \% \mathrm{CI}=-20.74 \sim-7.07$; $\mathrm{p}$ $=0.001,95 \% \mathrm{CI}=-0.71 \sim-0.21$, respectively) (Table 2). In the dynamic balance ability assessment, there was a significant difference in the limits of stability in the single leg test (p $=0.047,95 \% \mathrm{CI}=6.57 \sim 740.60)$ (Table 2). There was a significant difference in MFRT between the two groups ( $\mathrm{p}=0.007,95 \% \mathrm{CI}=1.31 \sim 7.24)$, however there was no significant differences in the FRT between the two groups ( $p=0.874,95 \%$ CI $=-4.71 \sim 4.03$ ) (Table 3).

\section{Discussion}

We investigated the effects of functional instability of the ankle joint when balancing by comparing the static and dynamic balance abilities of individuals with instabilities (AFI group) and those without them (AFS). Many terms have been used to describe repetitive ankle sprains including; functional instability, chronic instability and residual instability which has led to confusion in terminology[22]. The participants with the ankle instability are mostly young people who were in good health and without any limitations in their daily activities. Therefore it was decided to use the ankle functional instability as a definition of repetitive ankle sprains. Regarding static balance, there were no significant differences in the mean 
velocity of the pressure centre in the single leg standing test between the two groups.

However, the AFI group had significantly reduced static and dynamic balance when compared to the AFS group. The limits of stability during the single leg test and MFRT showed that the AFS group had significantly greater balance abilities than the AFI group ( $<<$ 0.05). However, there were no significant differences in the surface area of the ellipse in the single leg standing test and the FRT, between the two groups.

The single leg standing test for the static balance assessment conducted on the BioRescue was used to determine the balance abilities based on the level of postural sway. This measured the length of the pressure centre trajectory, the mean velocity of the pressure centre, and the surface area of the ellipse[23,24]. One possible reason that there was not a significant difference in the surface area of the ellipse in the single leg standing test between the two groups, was that the FAI group did not have any significant difficulties in performing daily activities compared to the FAS individuals despite having instability of the ankle joints. In addition, the surface area of the ellipse assessed the overall movement area of the centre of the pressure during postural sway, which could lack sensitivity for measuring specific unstable events during static posture compared to other measurement variables.

There were no significant differences in FRT, as a dynamic balance assessment between the two groups, whereas there was a significant difference in MFRT. FRT measures the anterior and posterior stability of ankle joints and is mainly affected by the muscle 
strength of the plantar flexor[17]. Winter et al.[25] reported that improvements in FRT reflected the control abilities in the anterior and posterior directions of the dominant foot in the ankle joint. However, most ankle joint functional instabilities reduce medial and lateral stability due to damage in the anterior talofibular ligament, which is a lateral ligament[26]. FRT reflects anterior and posterior stability to a greater extent than medial and lateral stability in ankle joints, therefore, no significant difference in balance abilities was seen between the two groups. However, MFRT reflects medial and lateral stability to a greater extent than anterior and posterior stability. Therefore, the MFRT appears to be more suitable for assessing dynamic balance with respect to the lateral stability of the ankle joint and the present study suggests that the MFRT may be a quick and inexpensive clinical measure of postural instability of the ankle joint. The Star Excursion Balance Test (SEBT) is a functional test that incorporates a single-leg stance on one leg whilst trying to reach as far as possible with the opposite leg. This has previously been used to evaluate dynamic postural control in individuals with chronic ankle instability[27,28]. Previous studies have reported differences in reach distances between lower limbs on the SEBT, which has been found to be sensitive in identifying in individuals with ankle instability[27-29]. In addition, the method and result of the limit of stability in the single leg test used in this study were similar to the SEBT used in previous studies[27-29]. Therefore, further studies should use the MFRT and the SEBT to determine the effectiveness of clinical intervention that targets improvements in balance. 
The above results support the hypothesis of this study: that individuals who have instability in their ankle joints have inferior static and dynamic balance compared to normal individuals. The limitations of this study were as follows: First, the number of individuals was small and therefore we were unable to explore if subgroups existed in the ankle joint instability group. Also, participants were generally otherwise healthy university students without any limitations in their daily activities. Thus, our results may not represent all ankle joint functional instabilities. Second, a shortcoming was that an assistant was present to protect subjects from falling during the balance test which may have reduced the effect of fear of falling. Thus, it is necessary to find a new experimental method that can overcome these limitations and to verify effective physical therapy methods for subjects who have functional ankle joint instability. Therefore, we suggest that further studies should use the various functional tests which might be better at identifying individuals with ankle instability as they can more closely replicate usual physical activity and provide a more relevant assessment of joint stability, strength, and sensorimotor function. 


\section{References}

[1] Freeman MA. Instability of the foot after injuries to the lateral ligament of the ankle. $\mathrm{J}$ Bone Joint Surg Br. 1965;47:669-77.

[2] Harrington KD. Degenerative arthritis of the ankle secondary to long-standing lateral ligament instability. J Bone Joint Surg Am. 1979;61:354-61.

[3] Stephens MM, Sammarco GJ. The stabilizing role of the lateral ligament complex around the ankle and subtalar joints. Foot Ankle 1992;13:130-6.

[4] Ebig M, Lephart SM, Burdett RG, Miller MC, Pincivero DM. The effect of sudden inversion stress on EMG activity of the peroneal and tibialis anterior muscles in the chronically unstable ankle. J Orthop Sports Phys Ther. 1997;26:73-7.

[5] Wright IC, Neptune RR, van den Bogert AJ, Nigg BM. The influence of foot positioning on ankle sprains. J Biomech. 2000;33:513-9.

[6] Konradsen L, Olesen S, Hansen H. Ankle sensorimotor control and eversion strength after acute ankle inversion injuries. Am J Sports Med. 1998;26:72-7.

[7] Caulfield B. Functional instability of the ankle features and underlying causes. Physiotherapy. 2000;86:401-11. 
[8] McGuine TA, Greene JJ, Best T, Leverson G. Balance as a predictor of ankle injuries in high school basketball players. Clin J Sport Med. 2000;10:239-44.

[9] Mckeon PO, Hertel J. Systematic review of postural control and lateral ankle instability, part I: can deficits be detected with instrumented testing. J Athl Train. 2008;43:293-304.

[10] Kim YW. Correlation between the sensory organization test and the functional reach test for balance evaluation of elderly individuals. J Phys Ther Sci. 2012;24:675-9.

[11] Eils E, Rosenbaum D. A multi-station proprioceptive exercise program in patients with ankle instability. Med Sci Sports Exerc. 2001;33:1991-8.

[12] Lord SR, Clark RD, Webster IW. Postural stability and associated physiological factors in a population of aged persons. J Gerontol. 1991;46:M69-76.

[13] Blackburn T, Prentice WE, Guskiewicz KM, Busby MA. Balance and joint stability: the relative contributions of proprioception and muscular strength. J Sport Rehabil. 2000;9:31528.

[14] De Ridder R, Willems TM, Vanrenterghem J, Roosen P. Effect of tape on dynamic postural stability in subjects with chronic ankle instability. Int J Sports Med. 2015;36:321-6.

[15] Wortmann MA, Docherty CL. Effect of balance training on postural stability in subjects with chronic ankle instability. J Sport Rehabil. 2013;22:143-9. 
[16] Hadadi M, Mazaheri M, Mousavi ME, Maroufi N, Bahramizadeh M, Fardipour S. Effects of soft and semi-rigid ankle orthoses on postural sway in people with and without functional ankle instability. J Sci Med Sport. 2011;14:370-5.

[17] Daubney ME, Culham EG. Lower-extremity muscle force and balance performance in adults aged 65 years and older. Phys Ther. 1999;79:1177-85.

[18] Gribble PA, Delahunt E, Bleakley CM, Caulfield B, Docherty CL, Fong DT, Fourchet F, Hertel J, Hiller CE, Kaminski TW, McKeon PO, Refshauge KM, van der Wees P, Vicenzino W, Wikstrom EA. Selection criteria for patients with chronic ankle instability in controlled research: a position statement of the International Ankle Consortium. J Athl Train. 2014 JanFeb;49:121-7.

[19] Ross SE, Guskiewicz KM, Gross MT, Yu B. Assessment tools for identifying functional limitations associated with functional ankle instability. J Athl Train. 2008;43:44-50.

[20] Duncan PW, Weiner DK, Chandler J, Studenski S. Functional reach: a new clinical measure of balance. J Gerontol, 1990;45:M192-7.

[21] Katz-Leurer M, Fisher I, Neeb M, Schwartz I, Carmeli E. Reliability and validity of the modified functional reach test at the sub-acute stage post-stroke. Disabil Rehabil. 2009;31:243-8 
[22] Hertel J. Functional Anatomy, Pathomechanics, and Pathophysiology of Lateral Ankle Instability. J Athl Train. 2002;37:364-75.

[23] Kim JH, Kim YE, Bae SH, Kim KY. The effect of the neurac sling exercise on postural balance adjustment and muscular response patterns in chronic low back pain patients. J Phys Ther Sci. 2013;25:1015-9.

[24] Lee YM, Jang C, Bak IH, Yoon JS. Effects of computer-assisted cognitive rehabilitation training on the cognition and static balance of the elderly. J Phys Ther Sci. 2013;25:1475-7.

[25] Winter DA, Patla AE, Prince F, Ishac M, Gielo-Perczak K. Stiffness control of balance in quiet standing. J Neurophysiol. 1998;80:1211-21.

[26] Eils E, Demming C, Kollmeier G, Thorwesten L, Völker K, Rosenbaum D. Comprehensive testing of 10 different ankle braces. Evaluation of passive and rapidly induced stability in subjects with chronic ankle instability. Clin Biomech (Bristol, Avon). 2002;17:526-35.

[27] Nakagawa L, Hoffman M. Performance in static, dynamic, and clinical tests of postural control in individuals with recurrent ankle sprains. J Sport Rehabil. 2004;13:255-69.

[28] Hertel J, Braham RA, Hale SA, Olmsted-Kramer LC. Simplifying the star excursion balance test: analyses of subjects with and without chronic ankle instability. J Orthop Sports Phys Ther. 2006;36:131-7. 
[29] Olmsted LC, Carcia CR, Hertel J, Shultz SJ. Efficacy of the Star Excursion Balance Tests in Detecting Reach Deficits in Subjects With Chronic Ankle Instability. J Athl Train. 2002;37:501-6.

\section{Table Legends}

Table 1. General and clinical characteristics of the subjects $(\mathrm{N}=25)$

Table 2. Comparison of measures of single leg standing test and pendular test using BioRescue between groups $(\mathrm{N}=25)$

Table 3. Comparison of measures of the functional reach test and the modified functional reach test between groups $(\mathrm{N}=25)$

\section{Figure Legends}


Figure 1. The basic position of balance evaluation using BioRescue.

Figure 2. The evaluation of the single leg standing test was performed in a standing position. The subjects stood on the pressure plate of BioRescue and lifted one leg.

Figure 3. Figure 3. The functional reach test (A) and modified functional reach test (B).

Table 1. General and clinical characteristics of the subjects $(\mathrm{N}=25)$

\begin{tabular}{lccc} 
& $\begin{array}{c}\text { Ankle Stability Group } \\
(\mathrm{n}=15)\end{array}$ & Ankle Instability Group & $\mathrm{p}$ \\
\hline Age $(\mathrm{yrs})$ & $21.2 \pm 1.1^{\mathrm{a}}$ & $21.0 \pm 0.8$ & 0.62 \\
Height $(\mathrm{cm})$ & $166.3 \pm 8.1$ & $165.9 \pm 6.6$ & 0.89 \\
Weight $(\mathrm{kg})$ & $58.3 \pm 8.9$ & $58.6 \pm 10.5$ & 0.95 \\
Foot size & $245.7 \pm 12.4$ & $242.5 \pm 14.6$ & 0.57
\end{tabular}


$(\mathrm{mm})$

AJFAT

$3.8 \pm 5.5$

$29.6 \pm 2.5$

$0.00^{*}$

score

Abbreviations: AJFAT, Ankle joint functional assessment tool

${ }^{\mathrm{a}}$ Mean $\pm \mathrm{SD},{ }^{*} \mathrm{p}<0.05$.

Table 2. Comparison of measures of single leg standing test and pendular test using

BioRescue between groups $(\mathrm{N}=25)$

$\begin{array}{cccc}\text { Ankle Stability } & \text { Ankle } & & \text { 95\% Confidence } \\ \text { Group }(\mathrm{n}=15) & \text { Instability } & \text { p-value } & \text { Interval of the } \\ & \text { Group }(\mathrm{n}=10) & & \text { difference }\end{array}$

Single leg standing test

Surface area of the ellipse $\left(\mathrm{mm}^{2}\right) \quad 234.4 \pm 88.0 \quad 380.4 \pm 222.2^{\mathrm{a}} \quad 0.074 \quad-308.70 \sim 16.72$ 
Moving distance (cm)

Mean velocity $(\mathrm{cm} / \mathrm{s})$

Limits of stability test

Surface area of the ellipse $\left(\mathrm{mm}^{2}\right)$

$757.2 \pm 652.6$

$1.2 \pm 0.3$
$49.6 \pm 8.4$

$1.7 \pm 0.3$
$0.001^{*}$

$-20.74 \sim-7.07$

$0.001^{*}$

$-0.71 \sim-0.21$

${ }^{\mathrm{a}}$ Mean士SD, ${ }^{*} \mathrm{p}<0.05$

Table 3. Comparison of measures of the functional reach test and the modified functional reach test between groups $(\mathrm{N}=25)$

95\% Confidence

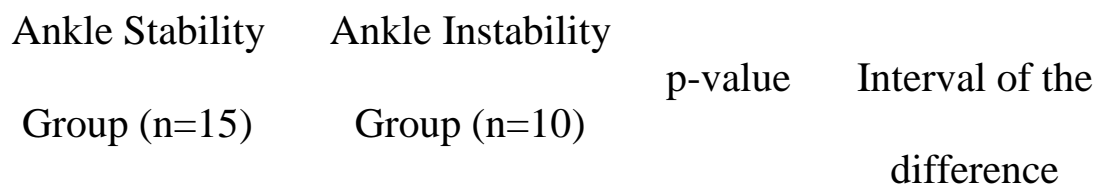

\begin{tabular}{lrrrc}
\hline FRT $(\mathrm{cm})$ & $19.6 \pm 3.4$ & $20.0 \pm 7.1^{\mathrm{a}}$ & 0.874 & $-4.71 \sim 4.03$ \\
MFRT $(\mathrm{cm})$ & $757.2 \pm 652.6$ & $383.6 \pm 116.9$ & $0.007^{*}$ & $1.31 \sim 7.24$ \\
\hline
\end{tabular}


Abbreviations: FRT, Functional reach test, MFRT, Modified functional reach test ${ }^{\mathrm{a}}$ Mean $\pm \mathrm{SD},{ }^{*} \mathrm{p}<0.05$

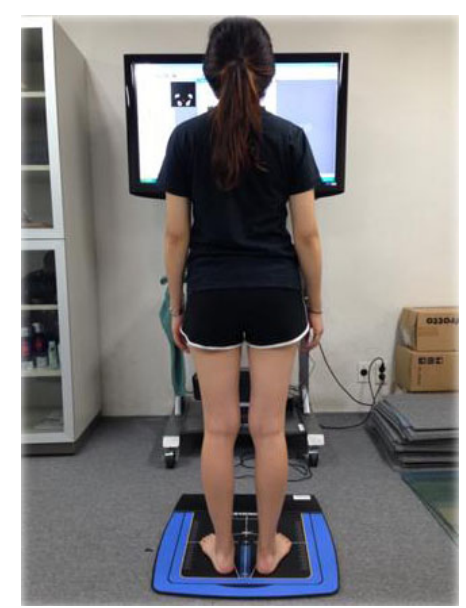

Figure 1. The basic position of balance evaluation using BioRescue. 


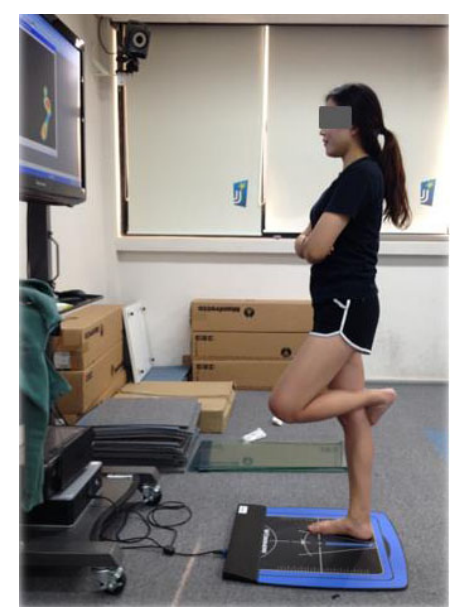

Figure 2. The evaluation of the single leg standing test was performed in a standing position. The subjects stood on the pressure plate of BioRescue and lifted one leg. 


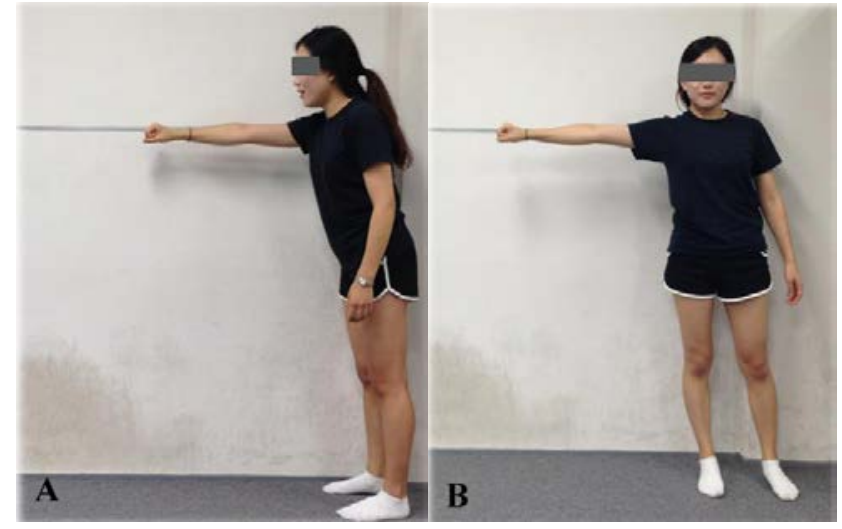

Figure 3. The functional reach test (A) and modified functional reach test (B). 